\title{
Small Signal Stability Analysis of Doubly Fed Induction Generator including SDBR
}

\author{
Mohammad Hasanuzzaman Shawon *, Ahmed Al-Durra * \\ Cedric Caruana* and S.M. Muyeen*
}

\begin{abstract}
This paper presents small signal stability analysis of a doubly fed induction generator (DFIG) based wind farm including series dynamic braking resistor (SDBR) connected at the stator side. A detailed mathematical model of wind turbine, DFIG machine and converters and SDBR is presented in this paper to derive the complete dynamic equations of the studied system. Small signal stability of this system is carried out by modal and sensitivity analysis, participation factors and eigenvalue analysis. Finally, this paper presents an analysis of the dynamic behavior of DFIG based wind farm under voltage dip condition with and without SDBR.
\end{abstract}

Keywords: Doubly fed induction generator (DFIG), Eigenvalue, Modal analysis, Rotor back EMF, Series dynamic braking resistor (SDBR), Sensitivity analysis, Small signal stability

\section{Introduction}

To meet the increasing power demand all over the world, wind energy is considered one of the most top growing and pollution free energy resources [1]. Among different topology available to obtain variable wind speed operation, doubly fed induction generator (DFIG) is quite popular now a days due to its reactive power controllability [2]. In doubly fed induction generator based wind energy conversion system, the stator winding is directly connected to the grid and the three phase rotor windings are supplied from a back to back voltage source converter via slip ring. This paper studies the behavior of the DFIG based wind farm which is modeled with the stator flux orientation. One salient feature of this study is to incorporate SDBR in the small signal stability model of DFIG based wind farm. The role of SDBR is to mitigate destabilizing depression of electrical torque and power during network disturbance [3]. The modeling of SDBR along with DFIG based system has seldom been reported in literature. The small signal stability analysis is carried by time domain simulation with and without SDBR. This study also attempts to develop a complete small signal stability model including SDBR which will be helpful to perform modal and sensitivity

\footnotetext{
* Dept. of Electrical Engineering, The Petroleum Institute. (hasan zaman04@yahoo.com,aaldurra@pi.ac.ae, ccaruana@pi.ac.ae,smmuyeen@pi.ac.ae) Received 12 January 2013; Accepted 12 February 2013
}

analyses, determining participation factors to find out the relations between different modes and state variables. The small signal stability analyses are carried out by time domain simulation with and without considering SDBR. This paper is organized as below: the dynamic model of variable speed wind turbine driven DFIG including SDBR is introduced in Section II. Then modal and sensitivity analyses are presented in Section III and IV. In Section V the dynamic behavior of the system under voltage dip with and without SDBR are examined. Conclusions are drawn in Section VI.

\section{Model System}

\subsection{System Configuration}

The schematic diagram of the studied system is presented in Fig. 1 where wind turbine driven doubly fed induction generator system is connected to power grid through the transmission line which may include the impedance of transformer and connection cable. The DFIG based wind power system is modeled using $5^{\text {th }}$ order machine model in which stator and rotor dynamics are considered. In addition, this model includes two-mass model of drive train to analyze the detail dynamic behavior of wind turbine driven DFIG based system. All the parameters are listed in appendix. 


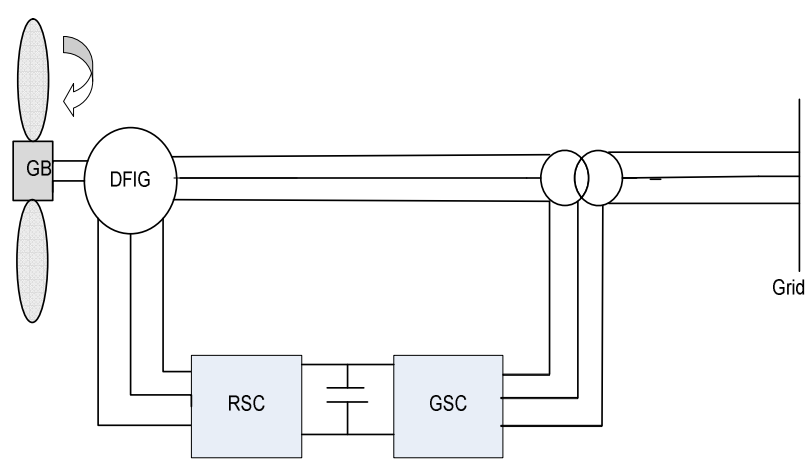

Fig. 1. On-line diagram of DFIG system connected with grid

\subsection{Drive Train Modeling}

Drive train model is developed in this section considering both the inertia of generator and turbine. The connecting shaft is modeled as a spring and damper. Fig. 2 shows simplified two-mass drive train models of wind turbine generator system. This study considers the simplified two-mass model which is sufficient for dynamic and transient analyses [4]

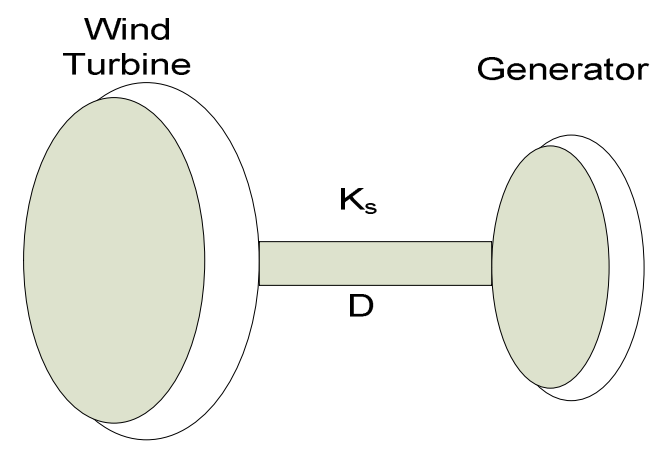

Fig. 2. Simplified two-mass model for wind turbine

The two-mass model is given by:

$$
\begin{aligned}
\left(2 H_{t}\right) \frac{d \omega_{t}}{d t} & =T_{m}-K_{s} \theta-D\left(\omega_{t}-\omega_{r}\right) \\
\left(2 H_{r}\right) \frac{d \omega_{r}}{d t} & =T_{e}+K_{s} \theta+D\left(\omega_{t}-\omega_{r}\right) \\
\frac{d \theta}{d t} & =\omega_{b}\left(\omega_{t}-\omega_{r}\right)
\end{aligned}
$$

where $\omega_{\mathrm{t}}$ and $\omega_{\mathrm{r}}$ is the pu angular speed of the turbine and $\mathrm{IG}$, respectively, $\mathrm{D}, \mathrm{K}_{\mathrm{s}}$, and $\theta$ are the mechanical damping coefficient $[\mathrm{pu}]$, spring constant $[\mathrm{pu}]$, and rotor angle difference between wind turbine and the IG [pu], respectively. $\mathrm{H}_{\mathrm{t}}$ and $\mathrm{H}_{\mathrm{r}}$ are the inertia constants (in seconds) of wind turbine and the IG respectively.

\subsection{DFIG System Modeling}

For modeling of DFIG, machine equations are represented in synchronously rotating reference frame with the help of direct (d) axis and quadrature (q) axis. For both stator and rotor negative sign represents currents out of the machine. To simplify the studied system, grid side converter and dc link are ignored. In this study, stator flux orientated control (SOFC) strategy is adopted and all the parameters and variables are considered in per unit. The stator, rotor, flux, electromagnetic torque, and reactive power equations are $[5,6]$ :

$$
\begin{gathered}
V_{s d}=R_{s} I_{s d}-\omega_{s} \psi_{s q}+\frac{1}{\omega_{b}} \frac{d \psi_{s d}}{d t} \\
V_{s q}=R_{s} I_{s q}+\omega_{s} \psi_{s d}+\frac{1}{\omega_{b}} \frac{d \psi_{s q}}{d t} \\
V_{r d}=R_{r} I_{r d}-\omega_{2} \psi_{r d}+\frac{1}{\omega_{b}} \frac{d \psi_{r d}}{d t} \\
V_{r q}=R_{r} I_{r q}+\omega_{2} \psi_{r d}+\frac{1}{\omega_{b}} \frac{d \psi_{r q}}{d t} \\
\psi_{s}=L_{s} I_{s}+L_{m} I_{r} \\
\psi_{r}=L_{m} I_{s}+L_{r} I_{r} \\
T_{e}=\frac{L_{m}}{L_{s}}\left(\psi_{s q} I_{r d}-\psi_{s d} I_{r q}\right) \\
Q_{s}=V_{s d} I_{s q}-V_{s q} I_{s d}
\end{gathered}
$$

where $V_{s}$ and $V_{r}$ are stator and rotor pu voltage, $L_{m}$ is the pu mutual inductance, $\mathrm{L}_{\mathrm{s}}$ and $\mathrm{L}_{\mathrm{r}}$ are stator and rotor pu self inductance, $R_{s}$ and $R_{r}$ are stator and rotor pu resistance, $\Psi_{\mathrm{s}}$ and $\Psi_{\mathrm{r}}$ are stator and rotor $\mathrm{pu}$ flux, $\omega_{\mathrm{s}}, \omega_{\mathrm{r}}, \omega_{2}$ are synchronous angular frequency, rotor angular frequency, and rotor slip frequency, all in $\mathrm{pu}, \omega_{\mathrm{b}}$ is the base angular frequency[377 $\mathrm{rad} / \mathrm{sec}]$ and $\mathrm{T}_{\mathrm{e}}, \mathrm{Q}_{\mathrm{S}}$ are pu electromagnetic torque and reactive power, respectively.

\subsection{Stator Modeling}

According to stator flux orientation $\Psi_{\mathrm{s}}=\Psi_{\mathrm{sd}}$ and $\Psi_{\mathrm{sq}}=$ 0 . Stator side of DFIG is presented with the help of rotor cu rrent, stator flux and stator voltage. Rotor current and stator flux variables can be used to build the state equations of st 
ator model.

$$
\begin{gathered}
\frac{1}{\omega_{b}} \frac{d \psi_{s d}}{d t}=-\frac{R_{s}}{L_{s}} \psi_{s d}+\frac{R_{s} L_{m}}{L_{s}} I_{r d}+V_{s} \cos \gamma \\
\frac{d \gamma}{d t}=\omega_{b}\left(\omega_{s}-\omega\right)
\end{gathered}
$$

where $\omega_{\mathrm{s}}$ is synchronous frequency and $\omega$ is speed of the dq reference frame, all in pu. $\gamma$ is denoted as the angle difference between the stator side voltage angle and stator flux angle with respect to stationary reference frame and $\mathrm{V}_{\mathrm{s}}$ is the stator voltage [pu].

\subsection{Rotor Modeling}

According to equation (9-12), stator and rotor voltages are depicted in terms of same reference frame. Using equation (9-12) and equation (13-14), the following equations are obtained

$$
\begin{gathered}
V_{s}=R_{s} I_{s}+\frac{1}{\omega_{b}} \frac{d \psi_{s d}}{d t}+j \omega_{s} \psi_{s} \\
V_{r}=R_{r} I_{r}+\frac{1}{\omega_{b}} \frac{d \psi_{r}}{d t}+j\left(\omega_{s}-\omega_{r}\right) \psi_{r}
\end{gathered}
$$

Substituting equation (14) into (15) and including the transient terms of stator flux, the following equation can be obtained

$$
\begin{gathered}
\frac{1}{\omega_{b}} \frac{d \psi_{s}}{d t}=V_{s}-\frac{R_{s}}{L_{s}} \psi_{s}+\frac{R_{s} L_{m}}{L_{s}} I_{r}-j \omega_{s} \psi_{s} \\
V_{r}=R_{r} I_{r}+\frac{L_{r}}{\omega_{b}} \sigma_{r} \frac{d I_{r}}{d t}+\frac{L_{m}}{L_{s}} \frac{d \psi_{s}}{d t}+j \omega_{2} \sigma L_{r} I_{r}+j \omega_{2} \frac{L_{m}}{L_{s}} \psi_{s}
\end{gathered}
$$

Substituting equation (16) into equation (17),

$$
V_{r}=R_{r}^{\prime} I_{r}+\frac{L_{r}}{\omega_{b}} \sigma_{r} \frac{d I_{r}}{d t}++j \omega_{2} \sigma L_{r} I_{r}+\frac{L_{m}}{L_{s}}\left(V_{s}-\frac{R_{s}}{L_{s}} \psi_{s}+j \omega_{r} \psi_{s}\right)
$$

Where, $R^{\prime}=R_{r}+L_{m}^{2} R_{s} / L_{s}^{2}$ and $\sigma_{r}=1-L_{m}^{2} / L_{r} L_{s}$ Rotor voltage equations are rewritten in terms of $\mathrm{d}$ q reference frame in the following equations

$$
\begin{gathered}
V_{r d}=R_{r}^{\prime} I_{r d}+\frac{L_{r}}{\omega_{b}} \sigma_{r} \frac{d I_{r d}}{d t}++j \omega_{2} \sigma L_{r} I_{r d}+E_{d} \\
V_{r q}=R_{r}^{\prime} I_{r q}+\frac{L_{r}}{\omega_{b}} \sigma_{r} \frac{d I_{r q}}{d t}++j \omega_{2} \sigma L_{r} I_{r q}+E_{q}
\end{gathered}
$$

where $\mathrm{E}_{\mathrm{d}}$ and $\mathrm{E}_{\mathrm{q}}$ are called rotor back EMF

$$
\begin{aligned}
& E_{d}=\frac{L_{m}}{L_{s}}\left(V_{s d}-\frac{R_{s}}{L_{s}} \psi_{s d}+j \omega_{r} \psi_{s d}\right) \\
& E_{q}=\frac{L_{m}}{L_{s}}\left(V_{s q}-\frac{R_{s}}{L_{s}} \psi_{s q}+j \omega_{r} \psi_{s q}\right)
\end{aligned}
$$

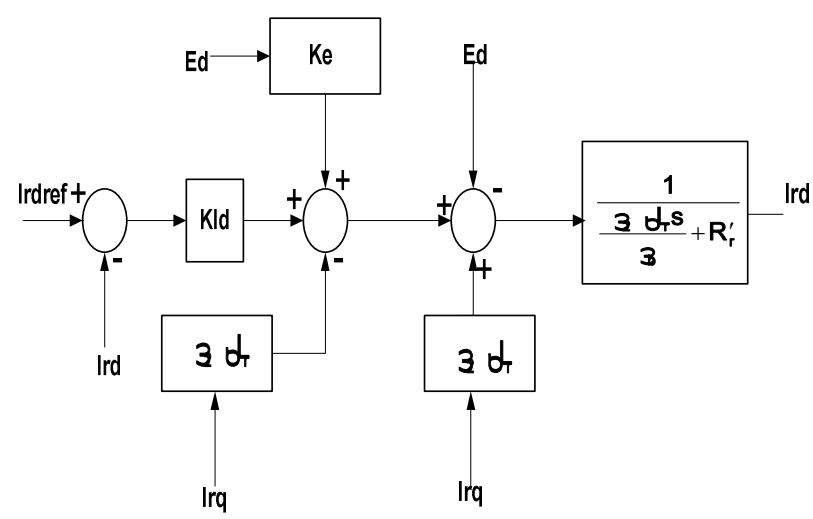

Fig. 3. d-axis rotor current controller

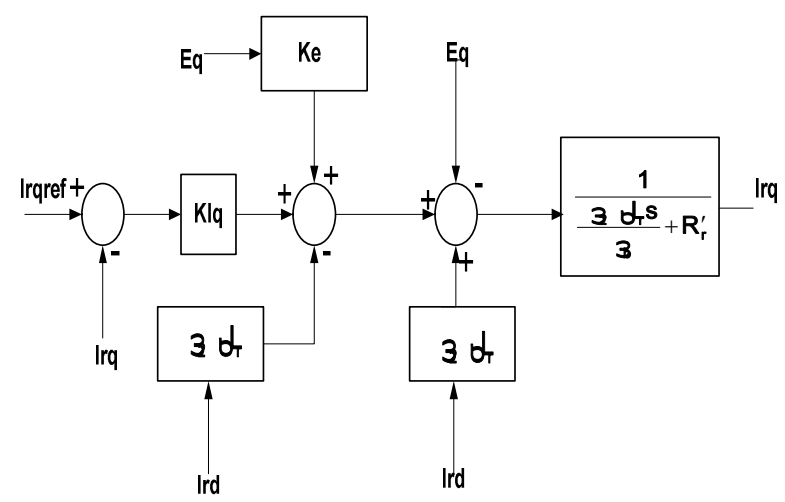

Fig. 4. q-axis rotor current controller

Ed and Eq represent effect of stator dynamic in rotor current dynamics. It is possible to decouple the cross coupling between the $\mathrm{d}$ and $\mathrm{q}$ axis components of the rotor current $-j \omega 2 \sigma \operatorname{LrIrd}$ and $j \omega 2 \sigma \operatorname{LrIrq}$ with the use of rotor current controller. Moreover, a feed forward compensating term is included in the control law that will compensate the tracking error caused by back EMF. Thus the rotor voltage can be stated as:

$$
\begin{gathered}
V_{r d}=K_{p} \cdot e_{r d}+K_{i} \cdot \int e_{r d} d t+j \omega_{2} \sigma L_{r} I_{r d}+K_{E} \cdot E_{d} \\
V_{r q}=K_{p} \cdot e_{r q}+K_{i} \cdot \int e_{r q} d t+j \omega_{2} \sigma L_{r} I_{r q}+K_{E} \cdot E_{q}
\end{gathered}
$$

where $e_{r d}=I_{r d r e f} I_{r d}$ and $e_{r q}=I_{r q r e f} I_{r q}$ and $\mathrm{K}_{\mathrm{p}}$ and $\mathrm{K}_{\mathrm{i}}$ are 
proportional gain and integral gain. A generic control law $\mathrm{KE}$ is introduced to include feed forward compensation term.

$$
K_{E}= \begin{cases}0 & \text { Without feed forward term } \\ 1 & \text { With feed forward term }\end{cases}
$$

Introducing active resistance to improve open loop bandwidth of the system, the state equation of rotor current can be stated as:

$$
\begin{aligned}
& \frac{\sigma \cdot L_{r}}{\omega_{b}} \frac{d I_{r d}}{d t}=-R_{r}^{\prime} I_{r d}+K_{p} \cdot e_{r d}+K_{i} \cdot \int e_{r d} d t+\left(K_{E}-1\right) \cdot E_{d}-R_{a} I_{r d} \\
& \frac{\sigma \cdot L_{r}}{\omega_{b}} \frac{d I_{r q}}{d t}=-R_{r}^{\prime} I_{r q}+K_{p} \cdot e_{r q}+K_{i \cdot} \cdot \int e_{r q} d t+\left(K_{E}-1\right) \cdot E_{q}-R_{a} I_{r q}
\end{aligned}
$$

The third and fourth term in equation (25) and (26) can be written as:

$$
\begin{aligned}
& \frac{d X_{5}}{d t}=K_{i} \cdot . e_{r d}=K_{i} \cdot\left(I_{r d r e f}-I_{r d}\right) \\
& \frac{d X_{6}}{d t}=K_{i} \cdot . e_{r q}=K_{i} \cdot\left(I_{r q r e f}-I_{r q}\right)
\end{aligned}
$$

\subsection{Speed Controller Modeling}

In stator flux orientation, the speed will be controlled by q-axis component of rotor voltage and current. Similar to current control loop, a PI controller can be employed in speed control scheme to track the reference speed. The equations for $\mathrm{q}$ axis reference current are stated as:

$$
\begin{gathered}
I_{r q r e f}=-K_{p \omega} \cdot\left(\omega_{r r e f}-\omega_{r}\right)-\int K_{i \omega} \cdot\left(\omega_{r r e f}-\omega_{r}\right)+D_{a} \omega_{r} \\
\frac{d X_{7}}{d t}=K_{i \omega} \cdot\left(\omega_{r r e f}-\omega_{r}\right)
\end{gathered}
$$

\subsection{Reactive Power Controller Modeling}

In stator flux orientation, the reactive power and terminal voltage will be controlled by d-axis component of rotor voltage and current. Similar to current control loop, a PI controller can be employed in reactive power control scheme to track the reference reactive power. The equations for $\mathrm{d}$ axis reference current are stated as:

$$
I_{r d r e f}=-K_{p q} \cdot\left(Q_{r e f}-Q\right)-\int K_{i q} \cdot\left(Q_{r r e f}-Q\right)
$$

$$
\frac{d X_{8}}{d t}=K_{i q} \cdot\left(Q_{r e f}-Q\right)
$$

where $\mathrm{Q}_{\mathrm{ref}}$ is the reference reactive power, $\mathrm{K}_{\mathrm{pq}}$ is proportional reactive power gain, and $\mathrm{K}_{\mathrm{iq}}$ is the integral reactive power gain.

\subsection{SDBR Modeling}

The SDBR contribute directly to the balance of active power during fault. SDBR modeling is accomplished by the insertion of a resistor in the stator circuit. Thus it increases the voltage at the terminal of DFIG and mitigates the destabilizing depression of electrical torque and power during fault [7]. Figure 5 shows schematic diagram of SDBR which is located in the stator side of the generator.

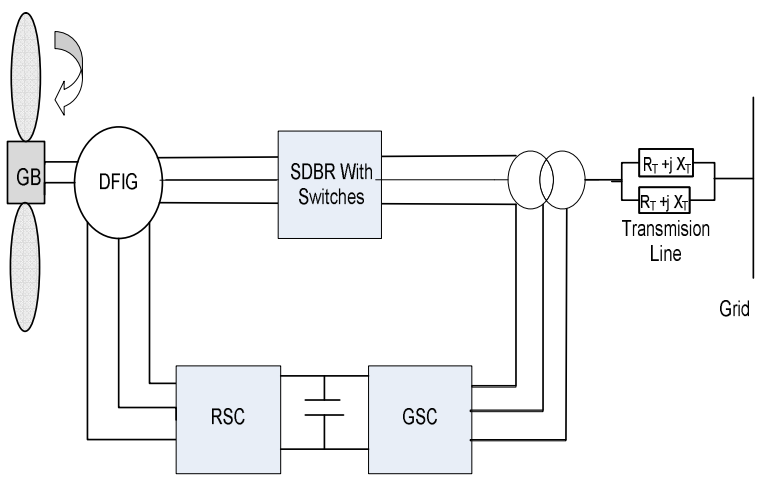

Fig. 5. Model System with SDBR

It can be seen from Fig. 6 that stator voltage $V_{\mathrm{s}}$ is increased due to the insertion of SDBR during fault. Since square of the stator voltage is proportional to mechanical power, SDBR will increase mechanical power and thus improve performance during voltage dip. Thus SDBR can be a very effective mean to enhance the dynamic performance of a DFIG based wind turbine generator.

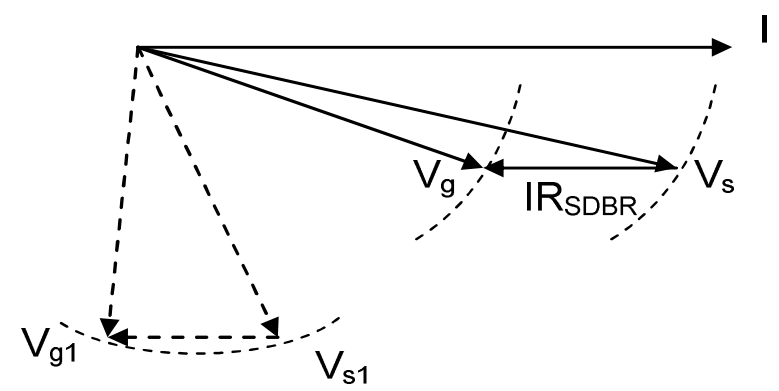

Fig. 6. Phasor diagram with effect on stator voltage 


\section{Small Signal Stability Analysis}

The mathematical model for each subsystem can be combined together to constitute a set of complete state space equations. The generalized nonlinear ordinary differential equations can be written in the following form [8]:

$$
\begin{aligned}
& 0=g(x, u) \\
& \dot{x}=f(x, u)
\end{aligned}
$$

where $x=\left[x_{1}, x_{2}, \ldots . x_{n}\right]^{T}, u=\left[u_{1}, u_{2}, \ldots . u_{n}\right], g=\left[g_{1}, g_{2}, \ldots . g_{m}\right]^{T}$. The $\mathrm{x}$ is referred as state vector, $\mathrm{u}$ is referred as input vector, $\mathrm{g}$ is referred as vector of nonlinear functions relating state and input variables to output variables.

The nonlinear equations developed in the previous section are first linearized around a nominal operating point to obtain a set of linearized equations that can be expressed by the following form:

$$
\begin{gathered}
0=C . \Delta X+D . \Delta U \\
\Delta \dot{X}=A . \Delta X+B . \Delta U
\end{gathered}
$$

The associate state variables are $X_{\text {DFIG }}=\left[\Psi_{\mathrm{sd}}, \gamma, \omega_{\mathrm{t}}, \omega_{\mathrm{r}}, \theta\right.$, $\left.\mathrm{I}_{\mathrm{rd}}, \mathrm{I}_{\mathrm{rq}}, \mathrm{X}_{5}, \mathrm{X}_{6}, \mathrm{X}_{7}, \mathrm{X}_{8}\right]^{\mathrm{T}}, \mathrm{U}=\left[\mathrm{T}_{\mathrm{m}}, \omega_{\mathrm{rref}}, \mathrm{Q}_{\mathrm{ref}}\right]$.

\subsection{Modal Analysis}

The modal analysis is performed on the system shown in Fig.1. Eigen values are studied in two cases: system with SDBR and system without SDBR. The system rating is used for this study is $4 \mathrm{MVA}, 690 \mathrm{~V}, 60 \mathrm{~Hz}$ variable speed wind generator connected with a grid.

Table 1. Eigenvalues of the studied system

\begin{tabular}{|l|l|l|}
\hline No. & Eigen Values & $\begin{array}{c}\text { Eigen Values(with } \\
\text { SDBR) }\end{array}$ \\
\hline$\lambda_{1}$ & $-2.68+\mathrm{j} 373.48 .3$ & $-32.82+\mathrm{j} 367.67 .8$ \\
\hline$\lambda_{2}$ & $-2.68-\mathrm{j} 373.48 .3$ & $-32.82-\mathrm{j} 367.67 .8$ \\
\hline$\lambda_{3}$ & $-371.23+\mathrm{j} 2.50$ & $-371.23+\mathrm{j} 55.80$ \\
\hline$\lambda_{4}$ & $-371.23-\mathrm{j} 2.50$ & $-371.23-\mathrm{j} 55.80$ \\
\hline$\lambda_{5}$ & -13.45 & -13.74 \\
\hline$\lambda_{6}$ & -15.64 & -15.25 \\
\hline$\lambda_{7}$ & -4.45 & -4.45 \\
\hline$\lambda_{8}$ & $-2.11+\mathrm{j} 11.35$ & $-2.11+\mathrm{j} 11.35$ \\
\hline$\lambda_{9}$ & $-2.11-\mathrm{j} 11.35$ & $-2.11-\mathrm{j} 11.35$ \\
\hline$\lambda_{10}$ & -0.65 & -0.65 \\
\hline$\lambda_{11}$ & -0.01 & -0.01 \\
\hline
\end{tabular}

\subsection{Participation Factor Analysis}

The system modes and corresponding participation factors are calculated in this section. By using participation factors the degree of contribution of each state variable in system modes are described.

a. Stator Modes: The mode $\lambda_{1}$ and $\lambda_{2}$ have the highest participation factor from $\Psi_{\text {sd }}$ and $\gamma$ and corresponding natural frequency is close to the network frequency.

b. Rotor Current Mode: The mode $\lambda_{3}$ and $\lambda_{4}$ are associated with the state variables $\mathrm{I}_{\mathrm{rd}}$ and $\mathrm{I}_{\mathrm{rq}}$. This mode is very fast and real part is approximately equal to rotor current closed loop bandwidth ( $1 \mathrm{pu}$ or $377 \mathrm{rad} / \mathrm{sec})$..

c. Rotor Electrical Mode: The mode $\lambda_{5}$ and $\lambda_{6}$ are associated with the state variables $\mathrm{X}_{5}$ and $\mathrm{X}_{6}$. The mode is closely related to rotor current open loop bandwidth .

d. Electromechanical Mode: The mode $\lambda_{7}$ and $\lambda_{8}$ are associated with the state variables $\omega_{\mathrm{r}}$ and $\theta$.

e. Real Mode: The mode $\lambda_{9}$ is associated with the state variables $\mathrm{X}_{6}$ and $\mathrm{X}_{8}$.

f. Weak Mechanical Mode: Mode $\lambda_{10}$ and $\lambda_{11}$ are associated with $\omega_{\mathrm{t}}$ and $\mathrm{X}_{7}$.

\section{Sensitivity Analysis}

Eigenvalue sensitivity indicates the rate and direction of eigenvalue displacement in the s-plane due to the variation in the system parameters which is an efficient tool for designing the control system and to parameterize the system. Eigen values and eigenvalues sensitivity are of high importance in analysis the instability phenomena given various circumstances. The first order sensitivity of an eigenvalue $\lambda_{i}$ with regard to a system parameter $\alpha$ is given by the following equations:

$$
\frac{\partial \lambda_{i}}{\partial \alpha}=\frac{\phi_{i}^{T}(\partial A / \partial \alpha) \psi_{i}}{\phi_{i}^{T} \psi_{i}}
$$

where $\Phi_{\mathrm{i}}$ and $\Psi_{\mathrm{i}}$ is the right and left eigenvector. The participation factor table 5.2 shows the degree of contribution of each state variable to the associate mode. For sensitivity analysis presented in this section rotor current closed loop bandwidth, rotor active damping, rotor current, rotor back EMF and transmission line will be considered. 


\subsection{Rotor Current Closed Loop Bandwidth}

With the increase of rotor current closed loop bandwidth, the rotor current dynamics will be improved as it decreases the tracking error and limits rotor current transients. It is a very important parameter to analysis the sensitivity of a DFIG based wind generator. However, stator mode is also related with rotor current closed bandwidth and this mode will be deteriorated with the increment of rotor current closed loop bandwidth. The sensitivity of stator mode with respect to rotor current control closed loop bandwidth of both $\mathrm{d}$ axis and $\mathrm{q}$ axis are given in the following:

$$
\begin{aligned}
& \frac{\partial \lambda_{1}}{\partial \alpha_{d}}=\frac{\partial \lambda_{1}}{\partial a_{1,1}} \cdot \frac{\partial a_{1,1}}{\partial \alpha_{d}} \\
& \frac{\partial \lambda_{1}}{\partial \alpha_{d}}=\frac{\partial \lambda_{1}}{\partial a_{3,3}} \cdot \frac{\partial a_{3,3}}{\partial \alpha_{q}}
\end{aligned}
$$

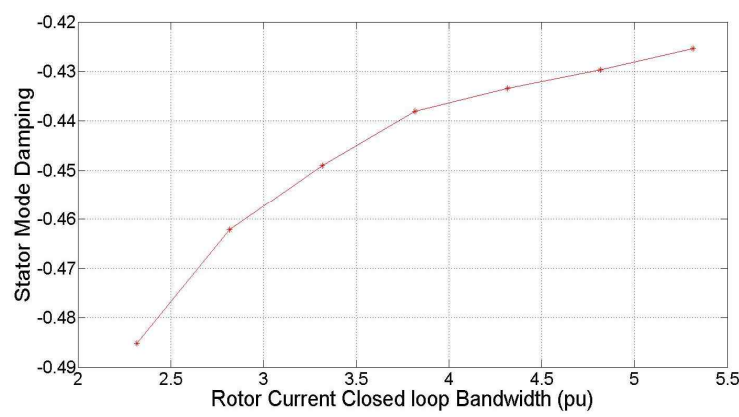

Fig. 7. Stator mode sensitivity with respect to rotor current bandwidth

From the Fig 7, it is clear that as the rotor current closed loop bandwidth increases, the damping of stator mode decreases and thus stability margin of stator mod also decreases.

\subsection{Rotor Active Damping}

The sensitivity of stator mode with respect to rotor current control closed loop bandwidth are given by the following equation:

$$
\frac{\partial \lambda_{1}}{\partial R_{\text {ractive }}}=\frac{\partial \lambda_{1}}{\partial a_{1,1}} \cdot \frac{\partial a_{1,1}}{\partial R_{\text {ractive }}}+\frac{\partial \lambda_{1}}{\partial a_{3,3}} \cdot \frac{\partial a_{3,3}}{\partial R_{\text {ractive }}}
$$

Active resistance is introduced in the rotor current controller scheme to increase the damping of the
disturbances.As the value of damping resistor in rotor current controller is increased, the damping of stator mode is significantly decreased while for rotor current mode the damping is significantly. This is a very important control parameter for DFIG based wind farm. The stability criteria for DFIG based wind farm also depends on this control parameter. Hence rotor active damping has been chosen for sensitivity analysis in this section.

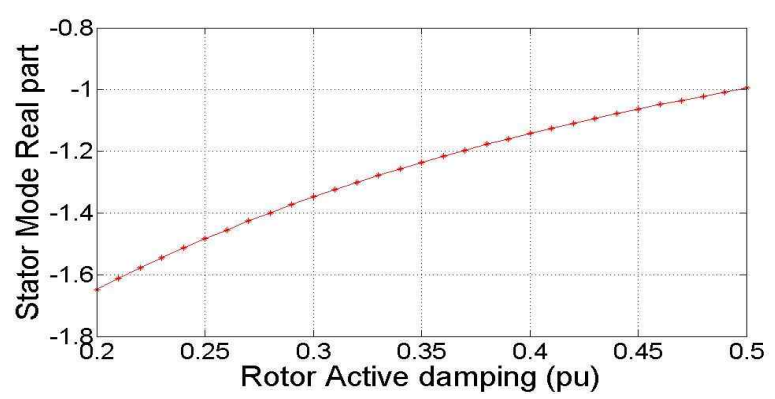

Fig. 8. Stator mode sensitivity with respect to rotor active damping

From the Fig 8, it is clear that the increment of rotor active damping resistor deteriorates the dynamics of stator mode as the damping of stator mode is decreased.

\subsection{Rotor Current}

The sensitivity of stator mode with respect to rotor current is described by the following equation:

$$
\frac{\partial \lambda_{1}}{\partial I_{r d}}=\frac{\partial \lambda_{1}}{\partial a_{11,11}} \cdot \frac{\partial a_{11,11}}{\partial I_{r d}}
$$

So increasing of rotor current (d-axis) will decrease the stator mode damping. Higher $d$ axis rotor current can lead stator mode to the unstable state and deteriorate system dynamics.

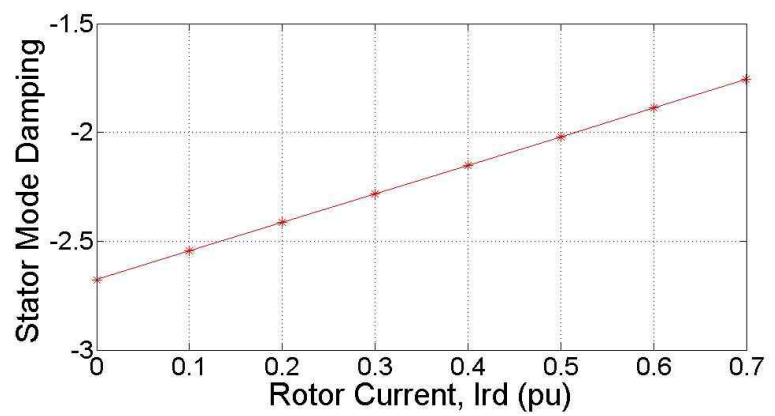

Fig. 9. Variation of stator mode damping with respect to rotor current 


\subsection{Transmission Line Parameter}

The sensitivity of stator mode with respect to rotor current is described by the following equation:

$$
\frac{\partial \lambda_{1}}{\partial R_{e}}=\frac{\partial \lambda_{1}}{\partial a_{2,2}} \cdot \frac{\partial a_{2,2}}{\partial R_{e}}+\frac{\partial \lambda_{1}}{\partial a_{2,1}} \cdot \frac{\partial a_{2,1}}{\partial R_{e}}
$$

Figure 10 shows that, SCR of network plays an important role in stator mode damping. From the fig 10, it is observed that increasing SCR of the network impedance will increase the damping of stator mode as well as increase stator mode stability margin.

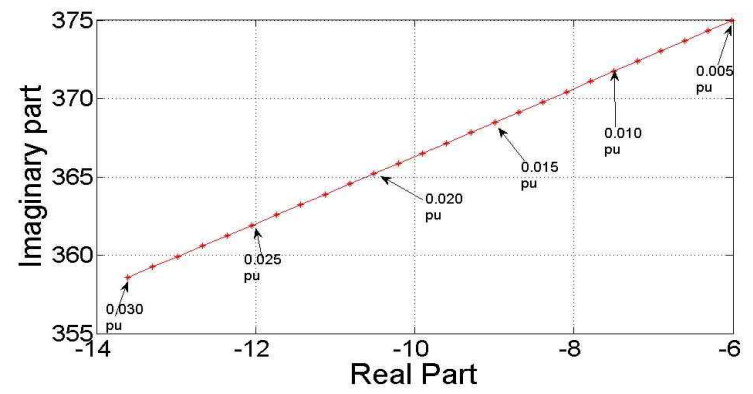

Fig. 10. Stator mode sensitivity with respect to transmission line

\section{System Dynamic Performance Under Voltage Dip Condition}

This section represents the dynamic performance of the studied system with and without considering SDBR under voltage dip condition. Figures 11-14 show comparative dynamic responses of the system under voltage dip with and without considering SDBR under a $300 \mathrm{~ms}$ voltage dip. The SDBR model is connected in the stator circuit of DFIG system. During voltage dip condition, it will increase the terminal voltage and assists the system to mitigate the destabilizing depression of electrical torque and thus improves system overall dynamic performance. It can be seen from Fig. 12 that, electrical torque has a very high fluctuation during voltage dip which should be kept within acceptable limit. But system with SDBR has showed better dynamic performances with less fluctuation and less settling time under voltage dip. Figure 13 demonstrates the stator flux response with and without SDBR.

Fig. 12 indicates that incorporation of SDBR reduces stator flux (d-axis) natural frequency of oscillation and improves damping as well. .The d-axis stator flux, rotor voltage (d-axis and q-axis) also showed better dynamic performance under voltage dip when SDBR is considered as seen from Figs. 12-14.

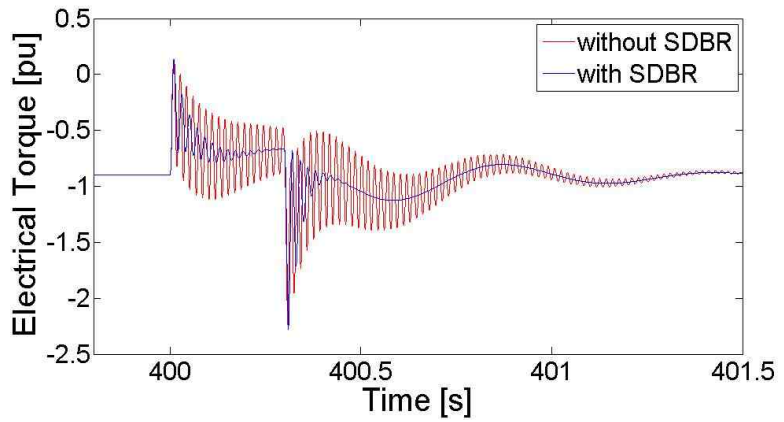

Fig. 11. Electrical torque response

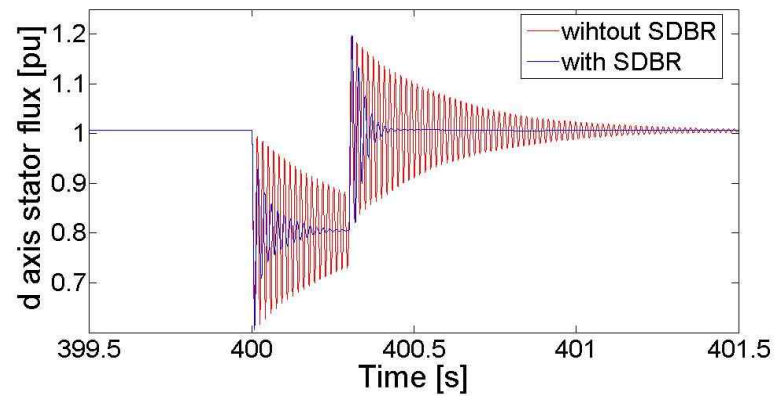

Fig. 12. Stator flux (d-axis) response)

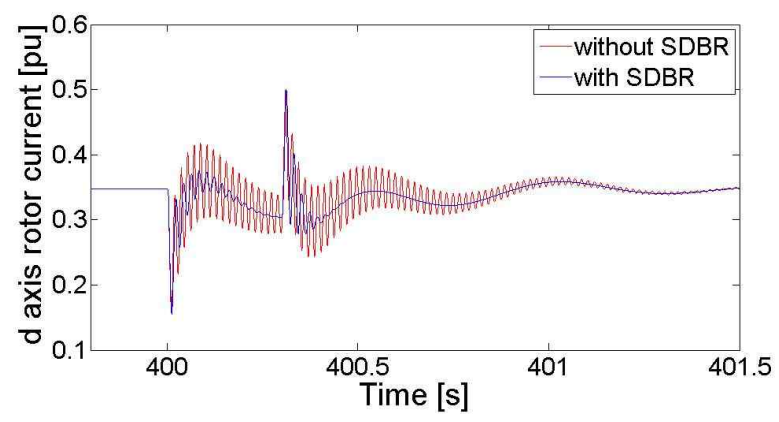

Fig. 13. Rotor current (d-axis) response

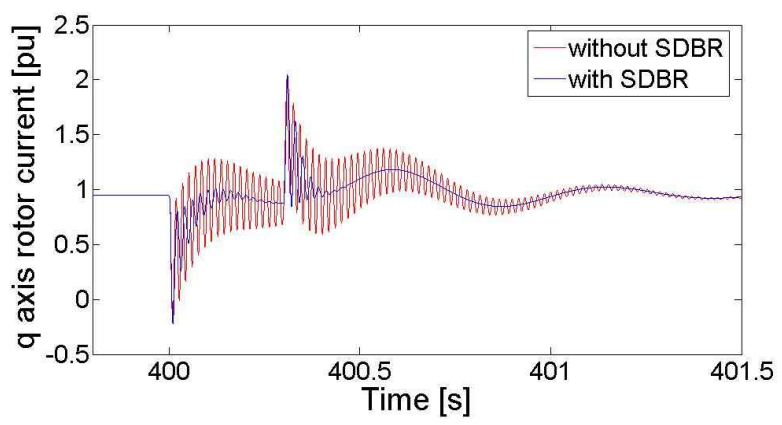

Fig. 14. Rotor current (q-axis) response 


\section{Conclusion}

Small signal stability analysis as well as augmentation of variable speed wind generator using a series dynamic braking resistor is the main focus of this study. Modeling of two mass drive train, stator and rotor side modeling, SDBR modeling is presented in this paper. For the sake of simplicity, grid side dynamics and dc link capacitor is ignored and it is assumed that converters are operated at unity power factor. Eigen value calculation as well as participation factor analysis has been utilized to evaluate the system behavior and system modes during small disturbances. Sensitivity analysis shows variation of eigenvalue with respect to the change of any system parameters. Dynamic responses of the system under voltage dip are demonstrated to validate the effectiveness of the proposed SDBR. This analysis will help to study the effects of system parameters on different modes, determining the stability margin and stability augmentation of wind farm composed of variable speed wind generators. The simulation results will be validated experimentally in future with a test rig system which is composed of wound rotor induction machine, back to back inverter including DC link, dSPACE 1103 based real time control using real time workshop

\section{Appendix}

\begin{tabular}{|c|c|}
\hline Parameters & Values \\
\hline Rated MVA & $4 \mathrm{MVA}$ \\
\hline Rated Voltage & $690 \mathrm{~V}$ \\
\hline Base Frequency & $377 \mathrm{rad} / \mathrm{sec}$ \\
\hline Stator resistance & $0.00706 \mathrm{pu}$ \\
\hline Rotor Resistance & $0.005 \mathrm{pu}$ \\
\hline Stator self inductance & $3.07 \mathrm{pu}$ \\
\hline Rotor self inductance & $3.056 \mathrm{pu}$ \\
\hline Magnetizing Reactance & $2.9 \mathrm{pu}$ \\
\hline Generatorinertia constant & $0.75 \mathrm{~s}$ \\
\hline Turbine inertia constant & $4.3 \mathrm{~s}$ \\
\hline Proportional gain & 0.3165 \\
\hline Integral gain & 4.256 \\
\hline Speed proportional gain & 6.98 \\
\hline Speed integral gain & 0.04656 \\
\hline Electrical Torque & $0.9 \mathrm{pu}$ \\
\hline V $_{\text {dgrid }}$ & $0 \mathrm{pu}$ \\
\hline V $_{\text {qgrid }}$ & $1 \mathrm{pu}$ \\
\hline
\end{tabular}

\section{References}

[1] International Wind Energy Development World Market Update,2009 J.[online].Available:http://btm.dk/public/Naviga nt_WMU2010ReportRelease.pdf.

[2] R Datta, and V. T. Ranganathan,"Decoupled Control of Active and Reactive Power for a Grid-Connected Doubly Wound Rotor Induction Machine Without Position Sensor," Conference Record of the1999 IEEE Industry Applications Conference, Thirty-Fourth IAS Annual Meeting (Cat. No. 99CH36370), pp. 2623-2628.

[3] A Causebrooke, D. J Atkinson and A.J Jack,"Fault ride through of large wind farms using series dynamic braking resistor (March 2007)," IEEE Trans. Power System, vol 22, no3, pp 966-975, August2007.

[4] S. M. Muyeen , M. H. Ali , R. Takahashi , T. Murata , J. Tamura , Y. Tomaki , A. Sakahara and E. Sasano"Transient stability analysis of wind generator system with the consideration of multi-mass shaft model", Proc. Int. Conf. Power Electron. Drives Syst., vol. 1, p.511, 2006.

[5] PC. Krause, Analysis of Electric Machinery. New York: MacGraw-Hill, 1987.

[6] J. Lopez, P Sanchis, X raboam, L Marroyo, Dynamic Behavior of doubly fed induction generator during three phase voltage dip, IEEE Trans, Energy Convers, vol. 22, pp. 709-717, 2007.

[7] W Freitas,AMorelato and W. Xu, "Improvement of induction generator stability using braking resistor," IEEE Trans. Power System,vol19., no. 2, pp. 1247-1249, March 2004.

[8] P. Kundur, Power System Stability and Control, MacgrawHill, Inc, 1994.

[9] Matlab/Simulink User's Guide, The Mathworks Inc, 2010.

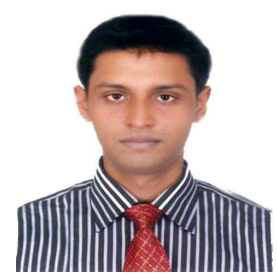

Mohammad Hasanuzzaman Shawon received M.Sc degree in Electrical Engineering from The Petroleum Institute, Abu Dhabi, United Arab Emirates. Prior to that, he completed his B.Sc in Electrical \& Electronics Engineering from Islamic University of Technology (IUT), Bangladesh. His research interests are wind energy and power system stability. He is a student member of IEEE.

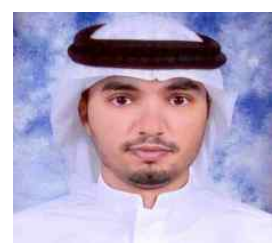

Ahmed Al Durra received the B.S., M.S., and $\mathrm{PhD}$ in Electrical and Computer Engineering from the Ohio State University in 2005,2007 , and 2010, respectively. His PhD work was on the applications of modern estimation and control theories to automotive propulsion systems." At the present, he is working as Assistant Professor in Electrical Engineering Department at the Petroleum Institute, Abu Dhabi. His research interests are application of estimation and control theory in power system stability and control, energy storage system (ESS), 
and renewable energy. Dr. Ahmed is a member of IEEE, and ASME.

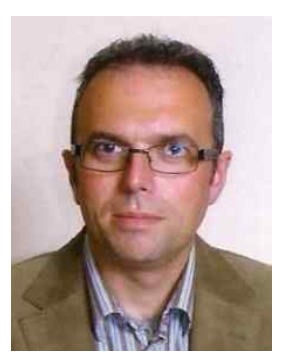

Cedric Caruana received the B.Eng (Hons) and M.Sc degrees from the University of Malta in 1994 and 2000 respectively. He received the Ph.D. degree from the University of Nottingham, U.K. in 2004 . His research interests include the control of electrical drives, renewable energy conversion, electrical machines and industrial energy efficiency.

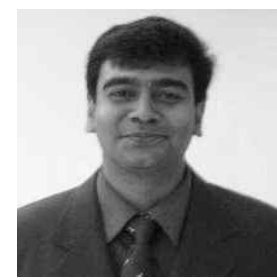

S.M. Muyeen received his B.Sc. Eng. Degree from Rajshahi University of Engineering and Technology (RUET), Bangladesh formerly known as Rajshahi Institute of Technology, in 2000 and M. Sc. Eng. and Dr. Eng. Degrees from Kitami Institute of Technology, Japan, in 2005 and 2008, respectively, all in Electrical and Electronic Engineering.After completing his Ph.D. program he worked as a Postdoctoral Research Fellow under the versatile banner of Japan Society for the Promotion of Science (JSPS) from 2008-2010 at the Kitami Institute of Technology, Japan. At the present, he is working as Assistant Professor in Electrical Engineering Department at the Petroleum Institute, Abu Dhabi. His research interests are power system stability and control, electrical machine, FACTS, energy storage system (ESS), Renewable Energy, and HVDC system. He has published over 100 international papers. He has published four books as an author or editor. Dr. Muyeen is the member of IEEJ and IEEE. 